\title{
Improving Disaster Risk Management According to Development Projects
}

\author{
Chang-Jae Kwak ${ }^{1}\left(\right.$ and Jung-Soo Kim ${ }^{2, *}$ \\ 1 National Disaster Management Research Institute, 1F, 406-33, Jongga-ro, Jung-gu, Ulsan 44538, Korea; \\ water203@korea.kr \\ 2 Department of Civil Engineering, Bucheon University, 25 Sinheung-ro 56 beon-gil, Bucheon-si 14632, Korea \\ * Correspondence: hydroguy@bc.ac.kr; Tel.: +82-32-610-3315
}

\section{check for}

updates

Citation: Kwak, Chang-Jae, and Jung-Soo Kim. 2021. Improving Disaster Risk Management According to Development Projects. Risks 9: 193 https://doi.org/10.3390/risks9110193

Academic Editor: Mogens Steffensen

Received: 10 September 2021

Accepted: 28 October 2021

Published: 2 November 2021

Publisher's Note: MDPI stays neutral with regard to jurisdictional claims in published maps and institutional affiliations.

Copyright: (c) 2021 by the authors. Licensee MDPI, Basel, Switzerland. This article is an open access article distributed under the terms and conditions of the Creative Commons Attribution (CC BY) license (https:/ / creativecommons.org/licenses/by/ $4.0 /)$.

\begin{abstract}
Since the 1990s, efforts have been made to reduce the damage caused by natural disasters, among which the Disaster Impact Assessment (DIA) System implemented in 1995 is noteworthy for its proactive response. The DIA System has undergone various institutional and technological changes to retain its original purpose. However, its operation has become inadequate because of the diversification of business types. This paper presents the improvements required in the DIA System based on an analysis of the problems that have emerged during its institutional development and over 9000 pieces of data collected from 2015 to 2017. The results show that, first, the DIA's Practical Guidelines should be subdivided, considering the diversity of projects. Second, the system should be strengthened to ensure it is not mistaken for a mere bureaucratic box-ticking exercise. Third, non-structural measures should be expanded to reduce the number of casualties after development. Incorporating the improvements proposed in this study will improve the effectiveness of the DIA. Additionally, the DIA System could be established as an important model for Korea's disaster risk reduction activities.
\end{abstract}

Keywords: disaster risk reduction activity; disaster impact assessment; disaster types; risk reduction measures

\section{Introduction}

The 2019 Global Natural Disaster Assessment Report (UNDRR Preventionweb 2020) indicated the following percentages for economic damage caused by natural disasters on a global scale: storm $47.53 \%$, flood $29.52 \%$, wildfire $21.28 \%$, earthquake $1.4 \%$, landslide $0.16 \%$, and drought $0.11 \%$. In the Republic of Korea (henceforth Korea), natural disasters have resulted in a total damage of USD 165 million and claimed seven lives in 2017. Between 2008 and 2017, 28 people were killed by typhoons and 124 by heavy rains, while 196,697 people were displaced. In addition, damage to buildings, agricultural land, and public facilities amounted to USD 3.78 billion (annual average of approximately USD 350 million). The percentage of property damage caused by heavy rain is $43 \%$, while that caused by typhoons is $46 \%$. Together, they comprise $89 \%$ of the total damage caused by natural disasters. To reduce the impact of such natural disasters in Korea, various efforts have been attempted from 1995 until the present day, including improvements (to the legal system, with assessment techniques, with disaster risk reduction policies, etc.) in disaster risk areas and small rivers, as well as the establishment of a storm reservoir. Approximately USD 7.33 billion of the national budget has been used for mitigation projects oriented toward disaster prevention. Among the various measures to reduce natural disasters, the most notable is the disaster impact assessment program, which estimates and evaluates the impact of natural disasters before permitting each administrative plan and development project to move forward.

Korea's representative impact assessment is constituted by the Environmental Impact Assessment (EIA) and Disaster Impact Assessment (DIA). In 1977, it adopted the 
EIA System, then titled "Prior Consultations", with the enactment of the Environmental Conservation Act. It was then introduced on a full scale in 1981, when the "Regulations on Preparing the EIA Report" were legislated. Over the past 40 years, the EIA has served as an effective program for protecting the environment while promoting awareness regarding environmentally friendly development among business operators (institutions) as well as promoting the importance of environmental conservation among the public (Ministry of Environment 2016).

While other countries evaluate the impacts of disasters due to development as detailed items of environmental impact assessment, damage after the occurrence of disasters, or disaster risk in preparation for disasters, Korea's DIA is different. Korea's DIA analyzes the impacts of natural disasters before commencing administrative plans and development projects. In operation since 1995, this system is based on Korea's Countermeasures Against Natural Disasters Act (No. 16101) and corresponds with Targets 11.3 and 11.5 of the Sustainable Development Goals to create sustainable cities and human settlements by reinforcing adaptation to climate change and resilience to natural disasters, reducing the number of deaths due to disasters, and decreasing direct economic losses.

As in the U.S., Japan, Germany, and other countries, Korea has operated the EIA since 1977; however, its EIA contains no items or contents for assessing the impacts of natural disasters in the six areas (Table 1). Both the DIA and the EIA assess potential impacts before approval of various plans or projects. However, there are differences in the major assessment items and contents between the DIA-which designates and assesses natural disaster items by type-and the EIA, which assesses environmental changes for assessment items regarding atmosphere, water environment, land, ecosystem, and social economy (Table 2).

Table 1. Comparison of EIA system by country.

\begin{tabular}{|c|c|c|c|c|}
\hline Division & Korea & U.S. & Japan & Germany \\
\hline Year introduced & 1977 & 1969 & 1972 & 1975 \\
\hline Assessment items & 6 areas & Select through scoping process & 4 areas & $\begin{array}{l}9 \text { areas } \\
\text { (Items are determined through scoping) }\end{array}$ \\
\hline Preparing entity & Business operator & Federal government & Business operator & State government, business operator \\
\hline
\end{tabular}

Table 2. Major DIA and EIA assessment items in Korea.

DIA (7 areas) River disaster, heavy rain disaster, slope disaster, ground disaster, coastal disaster, wind disaster, other disasters

The DIA shares the same purpose as international disaster risk reduction activities. It is a system that performs assessment before approval is given to development plans, with the aim of preventing and reducing frequently occurring natural disasters considering Korea's climate and topographical characteristics; moreover, sustained management and operation are essential for its success.

In order to continuously develop DIA, Korea attempted institutional integration with EIA in 2001, but failed to achieve good results; therefore, since 2005, DIA is operated independently again, expanding the target from 24 to 91 . In addition, in order to strengthen the legal binding, the law was revised thrice between 2001 and 2020, and the guidelines were revised seven times. Starting from 2024, there is a plan to promote the enactment of individual laws and regulations to operate the system independently. Despite these efforts, DIA has degenerated into a perfunctory process, because of the lack of institutional and case studies, limited legal processing period, operating principles based on written review, and lack of objectivity in data.

According to the 2010-2019 Korean Statistics (Ministry of the Interior and Safety 2020), the amount required for recovery from natural disasters is 2.3 times that of the damage 
caused. Even if the disaster reduction effects implemented in individual projects is not significant, the amount of damage and that required for the recovery from natural disasters will continue to increase, if disaster reduction efforts are not implemented in the 3000 development projects initiated annually. This study aimed to analyze the limitations of DIA; DIA is not properly utilized, because of the lack of operation and improvement in the legal system. Implementing DIA effectively could reduce the damage to development projects caused by natural disasters and propose directions for improvement, by evaluating them in an institutional framework.

The remainder of this paper introduces the purpose, change process, subjects of assessment, and assessment process of the DIA System; presents summary data regarding the operation status of the DIA System; and analyzes each element of the system. To derive improvement measures for the DIA System, past efforts for improvement and development of the system are described, and problems are analyzed through presentation of recent disaster cases. This paper also proposes major items required for the future development of the DIA System.

\section{Materials and Methods}

\subsection{Methods}

\subsubsection{Policy Classification of the DIA System}

Lowi (1972) classified policy types into the following: regulatory, distributive, redistributive, and constituent policies, focusing on the characteristics of the policy's social impact and the relationship between the participants in policy formation. Regulatory policies impose sanctions, control, and restrictions on individuals, businesses, and organizations to achieve public purposes. In addition, regulatory policies can be divided into economic and social regulations depending on their subject.

Social regulations can be classified by area as environmental (solving environmental pollution problems), industrial accidents (labor, industrial accident related), public protection (health, hygiene, safety, etc.), and social discrimination (discrimination against the disabled, women, and the socially disadvantaged).

The DIA System can be classified as a social regulation for public protection, which is imposed to provide greater protection against natural disasters. While natural conditions change through various development projects and an increase in impervious areas creates a flooding risk not only locally but also downstream, the failure to ensure proper measures (regulations) will harm people and their property.

\subsubsection{Evaluation of Regulatory Policies}

The assumption behind the question "How well is the regulation working?" is that "regulation is supposed to work"; it should improve social conditions. Evaluating a regulation after enforcement involves an investigation into how it has brought about a change in behavior and, ultimately, its impact on social conditions.

Coglianese (2012) noted that in most countries, regulatory impact analysis is actually undertaken at the pre-regulation stage, but in the post-regulation phase, it is neglected. In fact, measuring the effects of regulatory policies is very difficult and time-consuming. The ideal condition to measure the effectiveness of a policy is to select a random target for policy implementation and separate it from the one for which the policy will be implemented as a group. Then, conduct a comparative study of changes in behavior between policy implementation and control. However, it is difficult to introduce these experimental conditions into social science contexts. To assume these conditions and analyze policy effects, statistical techniques are sometimes employed, which should perform similarly to an actual case or qualitative analysis.

Radaelli and Fritsch (2012) evaluated the indicators of regulatory quality, focusing on regulatory management means and program assessment. Their research evaluated government capabilities to provide high-quality regulations across multiple sectors and on policy tools or supervisory activities that remain unchanged at the total level of regulatory activity. 
Improving regulatory quality is one of the tasks that many countries have consistently pursued as an important policy issue. Indeed, various methods, approaches, and models for reviewing existing regulations are widely used to achieve this objective (World Bank Group 2017). For example, the criteria can be reconstructed to fit Korea through examples from other countries (Cho 2006), as when a detailed analysis frame is created and evaluated (Sakong et al. 2000), or through a regulatory reform effectiveness assessment model focusing on cases by ministries (Lee et al. 2003).

In this paper, the objective, process, and operation status of the DIA System were investigated to assess how efficiently the system operates as a regulatory policy, using the evaluation framework presented by Cho (2006) (Table 3). The qualitative assessment was conducted, and the improvement points were presented based on the results.

Table 3. Evaluation Framework for DIA System.

\begin{tabular}{cc}
\hline Division & Description \\
\hline Openness & Transparency of regulations and procedures, political support, and collective participation \\
Fairness & Fairness at the procedural level, fairness in selection of target ranges, and formality for responsible materials \\
Generalness & The inclusiveness, non-discrimination, and perceived enterprise-wide reform of the government at a reform level \\
Professionality & A sense of balance on the technical capabilities of bureaucrats, regulatory choices \\
\hline
\end{tabular}

Source: Cho (2006).

\subsection{Purpose of the DIA}

The DIA is an institutional device designed to reduce disasters by examining in advance the appropriateness of various administrative plans and development projectssuch as complexes (dense areas of residential buildings and commercial buildings), tourist attractions, river projects, water supply and drainage projects, and rainwater runoff risk reduction projects-in terms of disaster, and by deliberating on disaster risk reduction measures. The positive aspects of preventing or reducing disasters can be anticipated by predicting hazardous areas or disaster risks in advance and establishing appropriate countermeasures. The current DIA System introduced the concept of disaster impact minimization from the administrative plans related to development, with the aim of overcoming the limitations of existing systems. Its main purpose, therefore, is to prevent or reduce disasters that can result from development.

\subsection{Subjects and Process of Assessment}

The administrative plans and development projects that are required to perform DIA are specified in Korea's Countermeasures Against Natural Disasters Act (No. 16101) (Ministry of Environment 2016) and classified into nine areas: (1) public, local, and urban development; (2) industrial and distribution complex development; (3) energy development; (4) transportation facilities construction; (5) use and development of rivers; (6) development of water resources and the ocean; (7) mountain development and aggregate collection; (8) tourism complex and sport facilities development; and (9) other plans and projects that influence natural disasters prescribed by the Countermeasures Against Natural Disasters Presidential Decree (No. 30256). As of 2018, there were 106 project types that needed to be assessed, including 47 administrative plans (e.g., urban planning) and 59 development projects (e.g., road construction).

\subsubsection{Assessment Items}

There are seven disaster areas for assessment: river, heavy rain, slope, ground, coast, wind, and other disasters. The scope of analysis for each disaster area within the scope of review in the Practical Guidelines for DIA (Ministry of the Public Administration and Security Notification No. 2019-5) (National Law Information Center 2019) is as follows.

The analysis scope of river disasters includes the following: analysis of the disaster vulnerability of river facilities such as levees according to the rise of river level inside and outside the target areas; analysis of the effect on disasters of structures (facilities) 
installed in the river (e.g., bridges); and analysis of the effect of waterway change of a river on disasters. The analysis scope of heavy rain disasters includes analysis of the possibility of inland flooding or river inundation due to increased runoff; analysis of sediment discharge due to development; analysis of discharge capacity and disaster impact of lateral drainage facility, etc.; and analysis of the damage possibility due to hydraulic structures in a development area.

The analysis scope of slope disasters includes analysis of the collapse possibility of cut slope, fill slope, or natural slope; and analysis of secondary disaster possibility (debris disaster) due to slope collapse (landslide). The analysis scope of ground disasters includes analysis of disaster possibility owing to soft ground subsidence and landfill; analysis of ground disaster possibility owing to groundwater exclusion and excavation, etc.; and analysis of ground collapse or subsidence owing to other causes.

The analysis scope of coastal disasters includes analysis of the possibility of coastal inundation; analysis of the disaster impact by coastal erosion; and analysis of disaster possibility due to rising tides owing to storm (or earthquake) surge. The analysis scope of wind disaster includes obligatory examination of disaster impact according to wind for high-rise facilities such as steel towers.

The analysis scope of other disasters includes subdivision and review of the scope of disasters in other disaster areas by closely observing the disaster types related to the corresponding plan; and solving the disaster impact that will be increased in the nearby area due to the plans and projects.

\subsubsection{DIA Consultation}

DIA consultation is conducted by a review committee composed of specialists (from academia, business, industry, etc.) in each disaster field from the consultation agency. ${ }^{1}$ The mode of consultation takes two forms: a written review and a face-to-face review. In the written review, review committee members note their opinions in written form and submit the results to the consulting organization. The face-to-face review is a way for the review members to meet at a specific place, submit their opinions, and submit the results decided through discussions.

While the administrative planning by central and local governments is conducted through written review consultations regardless of the size (area and length) of the target project, the DIA process as applied to development projects is divided into written reviews and face-to-face reviews based on the size of the target project (Table 4). However, although the consultation method for development projects is, in principle, divided according to target project size, the chairman of the review committee may decide on the method of consultation if necessary.

Table 4. Method of consultation by subject and size.

\begin{tabular}{cccc}
\hline \multirow{2}{*}{ Division } & \multicolumn{2}{c}{ Plan or Project Size } & Consultation Modes \\
\cline { 2 - 3 } & Area & Length & Written Review \\
Administrative Plans & - & - & Face-to-Face Review \\
Development Projects & Over $50,000 \mathrm{~m}^{2}$ & Over $10 \mathrm{~km}$ & Written Review \\
\hline
\end{tabular}

\subsubsection{DIA Procedure}

The DIA procedure can be divided into three stages, i.e., (1) preparation of an assessment report in accordance with the Practical Guidelines, (2) consultation of the project approved entity with the related central government department for the submitted assessment report, and (3) management of the content of consultation (Figure 1). 


\begin{tabular}{|c|c|}
\hline $\begin{array}{l}\text { Step 1: } \\
\text { Prepare assessment report }\end{array}$ & $\begin{array}{c}\text { Prepare an assessment report } \\
\left(\text { Business Operator }{ }^{2} \rightarrow \text { Approval Agency }^{3} \text { ) }\right.\end{array}$ \\
\hline \multicolumn{2}{|l|}{$\Downarrow$} \\
\hline $\begin{array}{l}\text { Step 2: } \\
\text { Perform consultation }\end{array}$ & $\begin{array}{l}\text { Assessment request (Approval Agency } \rightarrow \text { Consultation Agency) } \\
\text { Review \& Commission meeting (Consultation Agency) } \\
\text { Notify of assessment opinion (Consultation Agency } \rightarrow \text { Approval Agency) }\end{array}$ \\
\hline \multicolumn{2}{|l|}{$\Downarrow$} \\
\hline $\begin{array}{l}\text { Step 3: } \\
\text { Manage the content of } \\
\text { consultation }\end{array}$ & $\begin{array}{l}\text { Manage and supervise the implementation of consultation results } \\
\qquad \text { (Consultation Agency) }\end{array}$ \\
\hline
\end{tabular}

Figure 1. DIA operation procedure.

The aim of Step 1 (preparation of assessment report) is to predict the possible impacts of each disaster type for the major assessment items of the DIA, such as runoff, sediment discharge, and slope stability. The report must be written objectively and logically based on scientific facts, and its contents must be clear, concrete, and confirmed. Furthermore, the grounds for selection must be presented for survey area, survey point, prediction method, conditions for prediction, coefficients used for prediction, numerical values, etc., selected during the assessment.

Step 2 (consultation on disaster impacts) must be completed before the development commences; that is, the time for requesting consultation regarding the DIA is specified as "before approval" (or permission) of the target plan or project. According to the DIA assessment process, the business operator must submit the assessment report to the approval agency; after which the head of the approval agency requests a consultation with the head of the consultation agency. The head of the consultation agency must then chair a committee to deliberate the assessment report received for consultation and notify the approval agency of the result so that the business operator can carry out the necessary actions.

Step 3 (management of the content of consultation) requires the approval agency or consultation agency to manage and supervise the content of consultation so as to achieve the effectiveness of the DIA via the management and supervision of the business operator's obligations and content of consultation, notification of the project commencement, and prohibition of pre-construction.

The purpose and procedure of the DIA were previously introduced. For the next section, we collected about 9000 pieces of DIA data to analyze its operational status.

\section{Results: Overview of DIA Practice}

\subsection{Performance Results}

\subsubsection{Assessment Status According to Change of the System}

The first version of the DIA, implemented from 1996 to 2008, surveyed 24 business types, with a total of 636 cases. Since 2005, however, 38,709 cases of the second version of the DIA have been surveyed according to business type. This increase in the number of DIAs between the first and second versions occurred for two reasons: first, the number of business types has increased, and second, the standard for the scale in which consultations are conducted has expanded from $300,000 \mathrm{~m}^{2}$ in the first period to more than $5000 \mathrm{~m}^{2}$ in the second period. The period from 2005 to 2008 overlaps both the first and second periods as it was a transition phase in which a grace period was given to conclude the consultation management stage in the first period. 
The reason for the sharp increase since 2006 is the policy of the Korean government, which aimed for balanced regional development by moving public institutions to the provinces, an effect that lasted until 2009 (Figure 2). The impact of the related development projects continued until 2009; after 2017, the annual number of DIAs has reduced to approximately 3000 , a number that is expected to be maintained in the future.

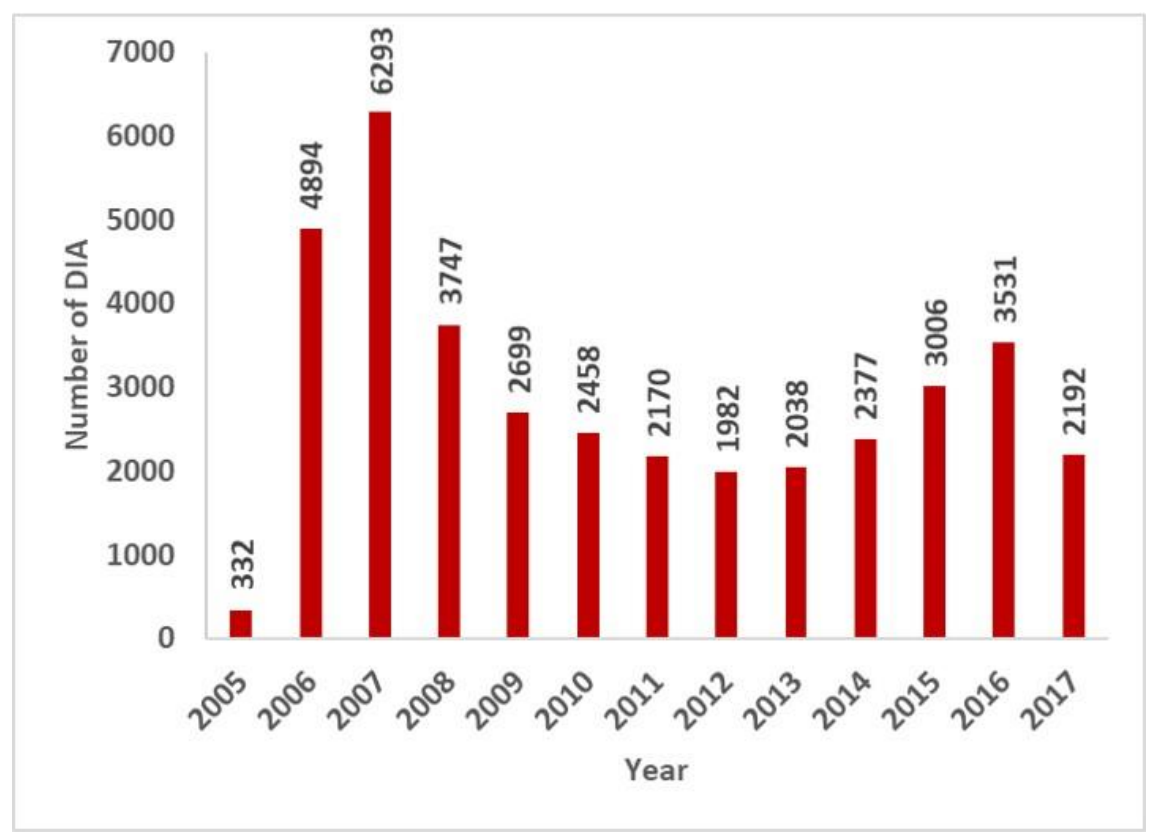

Figure 2. Frequency of Second DIAs completed by year.

\subsubsection{Assessment Results by Area and Region for the Period 2015-2017}

The number of consultations by area between 2015 and 2017 demonstrates that consultations are being conducted in all areas classified as subject projects of the DIA being generally conducted. However, as demonstrated in the consultation results of administrative plans by area, the consultations were much more concentrated on public, local, and urban developments (87\%) than on the other seven areas (13\%) (Figure 3).

On the other hand, the consultation results for development projects by area demonstrate balanced results, with $46 \%$ for public, local, and urban developments and $32 \%$ for mountain development and aggregate collection (Figure 3). The annual DIA results between 2015 and 2017 demonstrate that among the cities and provinces, Gyeonggi-do had the most results, followed by Gyeongsangbuk-do and Chungcheongbuk-do (Figure 4).

Among the metropolitan cities, Incheon demonstrated the largest number of results, followed by Busan and Ulsan. The fact that provinces demonstrated more results than metropolitan cities suggests that DIAs of administrative plans and development projects have increased in these particular provinces. In particular, Gyeonggi-do demonstrated much higher results than other provinces because many development activities have been conducted in urban subcenters due to the increased population density of the capital and rising house prices. 

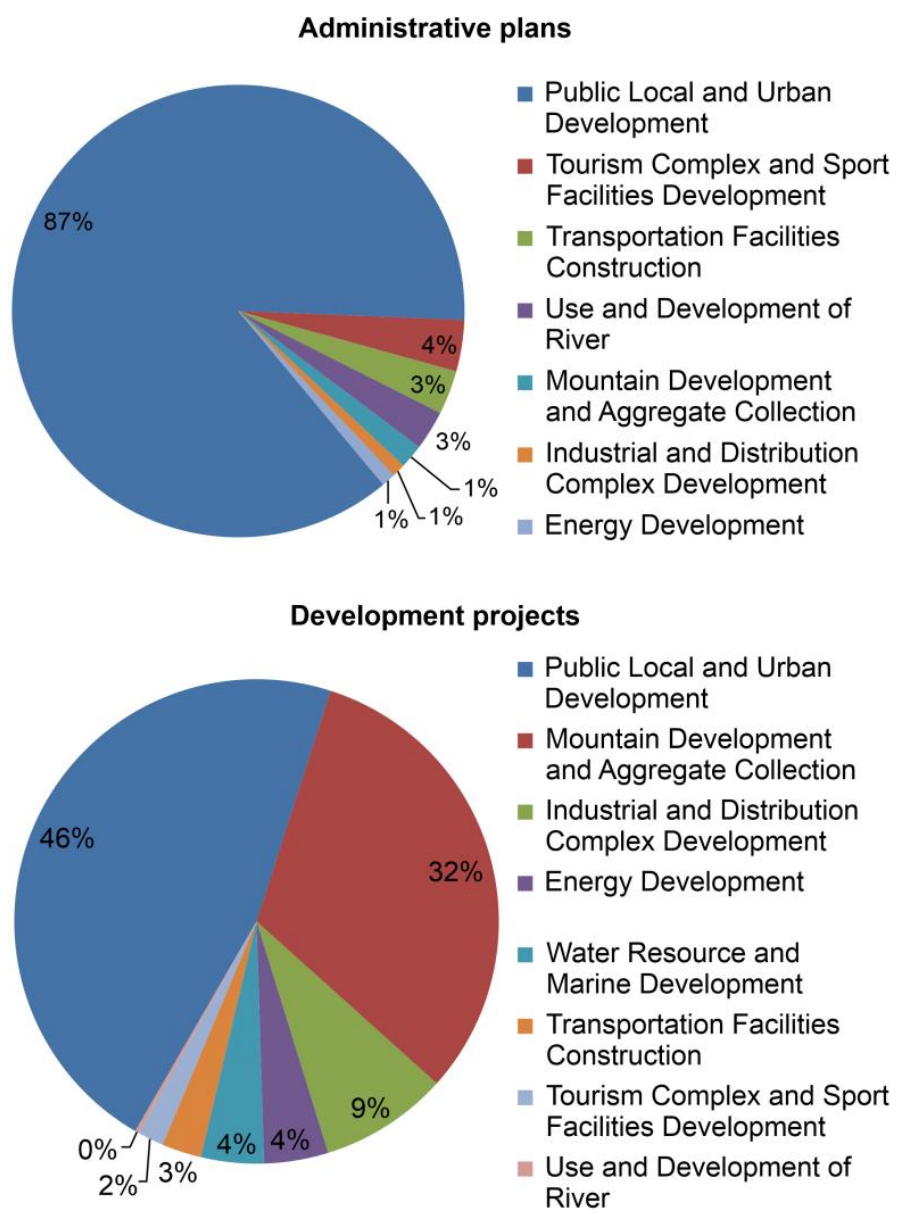

Figure 3. DIA results by area of administrative plans and development projects (2015-2017).

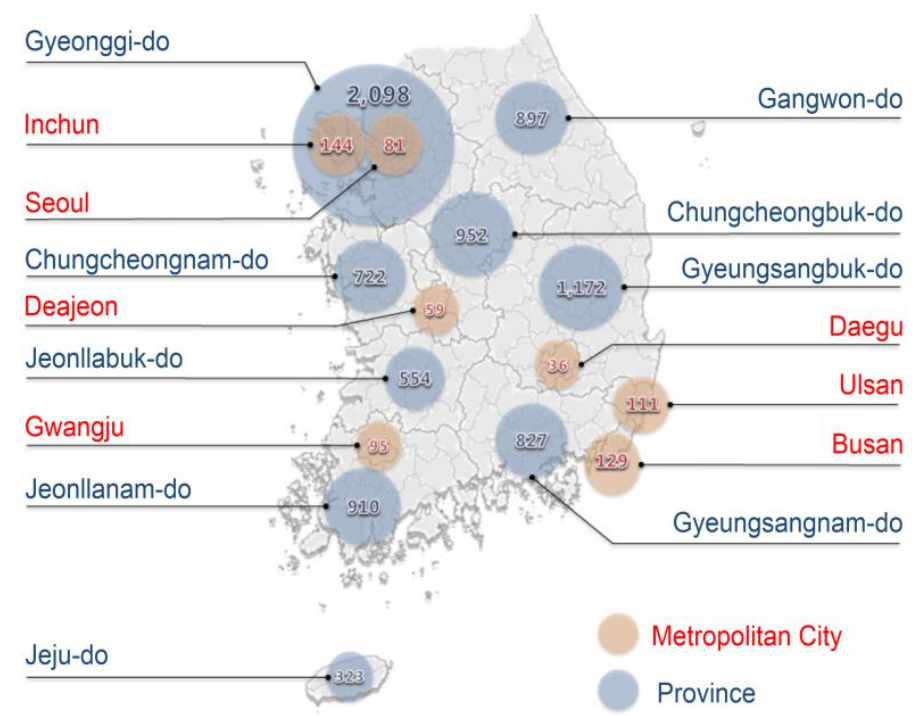

Figure 4. DIA results of metropolitan cities and provinces (2015-2017).

3.1.3. Consultation Modes and Results for 2015-2017

The results from 2015-2017 demonstrate that face-to-face review accounted for only $4 \%$ of the total; thus, it can be observed that meetings were generally conducted by written review regardless of the area size and length. If a written review is performed when 
disagreements occur regarding the same agenda, the measures for risk reduction may not be established properly because the committee members cannot reach a consensus.

Based on the analysis of the DIA results by area size, there were 50 DIAs for areas less than $5000 \mathrm{~m}^{2}, 2578$ for areas between $5000 \mathrm{~m}^{2}$ and 10,000 $\mathrm{m}^{2}, 4304$ for areas between $10,000 \mathrm{~m}^{2}$ and $50,000 \mathrm{~m}^{2}$, and 2008 for areas over $50,000 \mathrm{~m}^{2}$ (Figure 5).

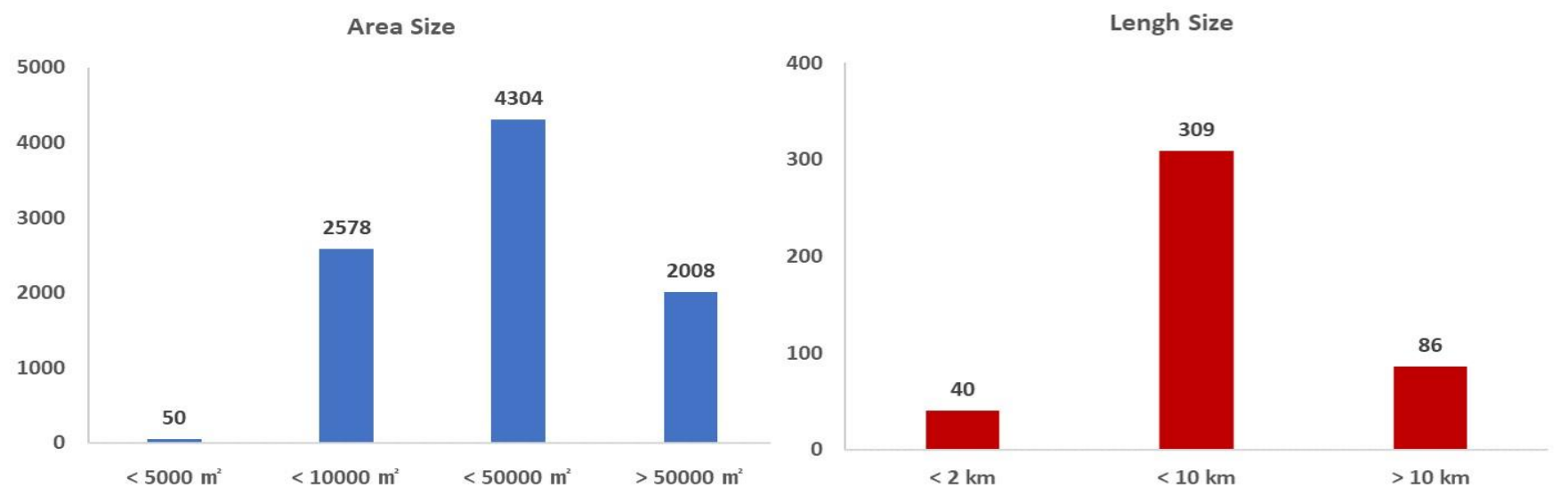

Figure 5. DIA results by area and length size (2015-2017).

Based on the analysis by length size, there were 309 DIAs for lengths between $2 \mathrm{~km}$ and $10 \mathrm{~km}$, and 86 for areas over $10 \mathrm{~km}$ (Figure 5). There were 50 DIAs for projects with a legal area size less than $5000 \mathrm{~m}^{2}$ and 40 DIAs for areas with a length less than $2 \mathrm{~km}$. Although these account for less than $1 \%$ of the total, they clearly reveal the problem of non-compliance with even the basic regulations of the DIA System.

Furthermore, the DIA results for 2015-2017 demonstrate that passage of the original bill accounted for $41 \%$, supplementation and revision accounted for $58 \%$, and rewriting for $1 \%$. Thus, almost all of the projects ultimately passed the assessment and came to be implemented (Figure 6).

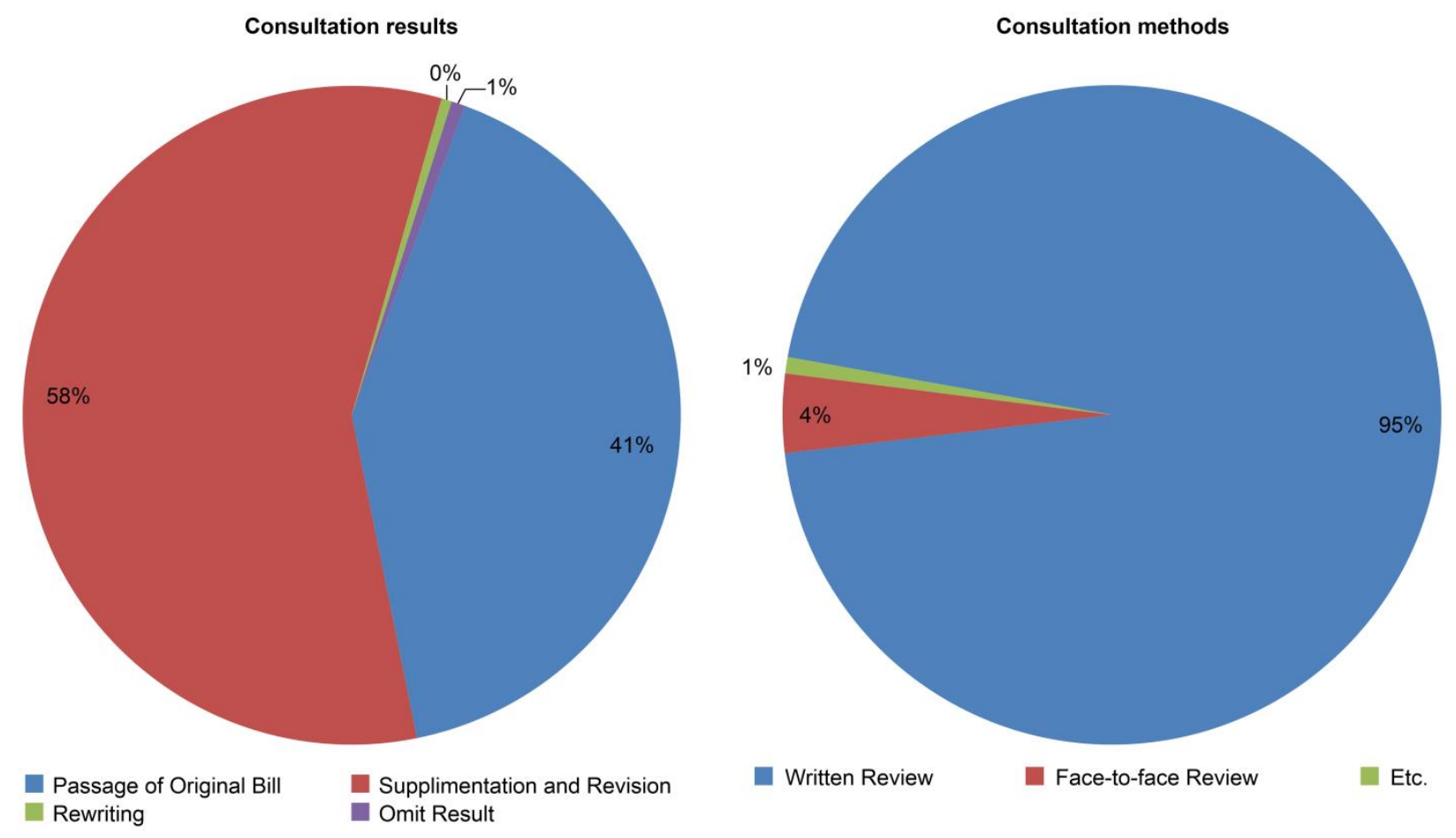

Figure 6. Consultation results and methods (2015-2017). 
As shown in Figure 6, one problem is that most consultations are conducted by written review, which results in a general lack of comprehensive and active reviews. Another problem is the legal procedure of the system, which requires that parties be informed of the result of consultation within 30 days thereof, leading to perfunctory processing.

\subsubsection{Post-Performance Inspection Results}

The performance management and supervision process of the consultation results, which is the final stage of the DIA, comprises the post-management phase that is performed twice in the first and second halves of each year. Workplaces with a construction progress rate of $10-80 \%$ in the current year are randomly selected and checked through a checklist. During the first half of 2018, 22 expert inspectors visited and inspected 235 workplaces in the central government departments for approximately 10 days. The main contents of the checklist consist of legal and administrative matters, and consultation performance status. The workplaces then receive action plans for poor inspection results and continuously manage them.

If the head of the consultation agency determines that the orders for consultation items based on the inspection results have not been implemented and will have a serious impact on disasters, he or she can issue an order to cease construction on all or part of the development project. However, no order to cease construction has been issued since the beginning of the system, despite concerns for disaster impact in some projects that demonstrated extreme disputes with NGOs or environmental groups, such as a radiation waste treatment plant, nuclear power plants, and military facilities.

Section 4 seeks to illustrate the problems of the DIA through examples and provide suggestions for improvements based on the summary analysis results of the DIA's operation status from Section 3.

\section{Discussion: Efforts to Improve the DIA}

\subsection{Background}

Among the measures established through the review committee, disaster prevention facilities serve as the primary disaster risk reduction facilities (National Law Information Center 2019). The measures proposed through the review committee have positive aspects such as preventing or reducing disasters by predicting and evaluating in advance dangerous areas or risks and establishing countermeasures. However, problems remain in terms of maintenance. For example, the performance of consultation items has come into question, as may occur in the installation of disaster risk reduction facilities, including temporary grit chambers and diversion waterways or the establishment of comprehensive measures via the interconnection of different departments or measures. Therefore, urgent solutions to these issues are necessary.

Kim (2007), noting that the distinction between projects subject to consultation under individual laws and projects for exceptions is ambiguous, proposed a plan to provide clear regulations for projects in addition to consultation under individual laws through practical guidelines and other measures. The National Disaster Management Institute (2009) proposed regular implementation and follow-up management if the review council proposes a measure that requires mandatory implementation suspension, completion of consultation for implementation inspection, and a measure that can be separately controlled for a certain time period (three years after completion of construction).

Park (2011) used previously consulted data to prove the validity of the consultation system by quantifying the disaster risk reduction effects, and derived improvement measures for the consultation modes. Park (2009) then investigated the status and improvement measures for the DIA disaster prevention facilities via an empirical analysis of the consulted review data and a survey of experts. Kang et al. (2014) presented improvement measures for the operation of the DIA System by dividing a total of 60 consultation cases, including 36 administrative plans and 24 development projects, into areas subject to consultation and location types. 
One problem of the DIA that has been noted in the research is that although the proportion of river and heavy rain disasters is very high in most projects, only structural countermeasures such as detention ponds and grit chambers are applied to these disasters. Since the purpose of the DIA System is to predict and review possible disasters in the development project sites and establish countermeasures, the disaster risk reduction facilities that are introduced must be installed in accordance with the corresponding design standards. However, using only structural measures has clear limitations because disasters such as typhoons and localized heavy rains occur with a return period exceeding the frequency presented in the design standards.

The activities to secure disaster prevention abilities are oriented toward the reinforcement of the disaster prevention performance of the systematic operation of structural and non-structural measures. The natural disaster risk reduction facilities are defined in Article 55 of Korea's Enforcement Decree of the Countermeasures Against Natural Disasters Act (No. 16101), but most correspond to structural measures. The disaster risk reduction factors presented in the DIA System can be classified into structural disaster risk reduction factors, such as heavy rain disaster risk reduction and slope stabilization measures, and non-structural disaster risk reduction measures, such as emergency action plans, public relations, and improvement of the legal system (National Law Information Center 2019).

The DIA System successfully prevents or reduces disasters resulting from administrative plans or development projects, by reviewing and consulting disaster risk analysis results or the adequacy of plans. Nevertheless, questions have been raised regarding the effectiveness of the system due to insufficient efforts to manage performance, such as disaster risk reduction through prevention of possible disasters during or after projects or installation and management of disaster safety facilities. According to the existing research, the main causes of these problems are that the contents of consultation are neither concrete nor quantifiable, and no system has been established for post-management and monitoring.

\subsection{Problems with the DIA}

The flooding damage (Figure 7) caused by Typhoon "Chaba" that struck Taehwa Market District in Ulsan in 2016 is a good example for presenting the major problems of DIA. The Residential Development District of Ulsan (B) was developed in 2010 when the district was designated a Development of Innovation City (A); ${ }^{2}$ a disaster impact assessment had been conducted in 2008. As a result of the DIA, the Development of Innovation City (A) installed Detention Storage (C) to reduce flood discharge. When Typhoon "Chaba" landed in Ulsan in 2016, the Taehwa River inundation and inland flooding from the upstream development projects (A and B) caused an inundation depth of $0.2 \mathrm{~m}$ to $1.6 \mathrm{~m}$ downstream of Taehwa Market District (D). Typhoon "Chaba" resulted in more than 10 casualties and damaged more than 3000 vehicles, while the first floor of Taehwa Market District (D) was flooded. There were three major causes of damage: (1) flooding of the Taehwa River due to record rainfall of 500 years or more, (2) insufficient measures to reduce inundation disasters in upstream development districts, and (3) absence of reducing facilities to exclude demand in low-lying areas (Taehwa Market District). 


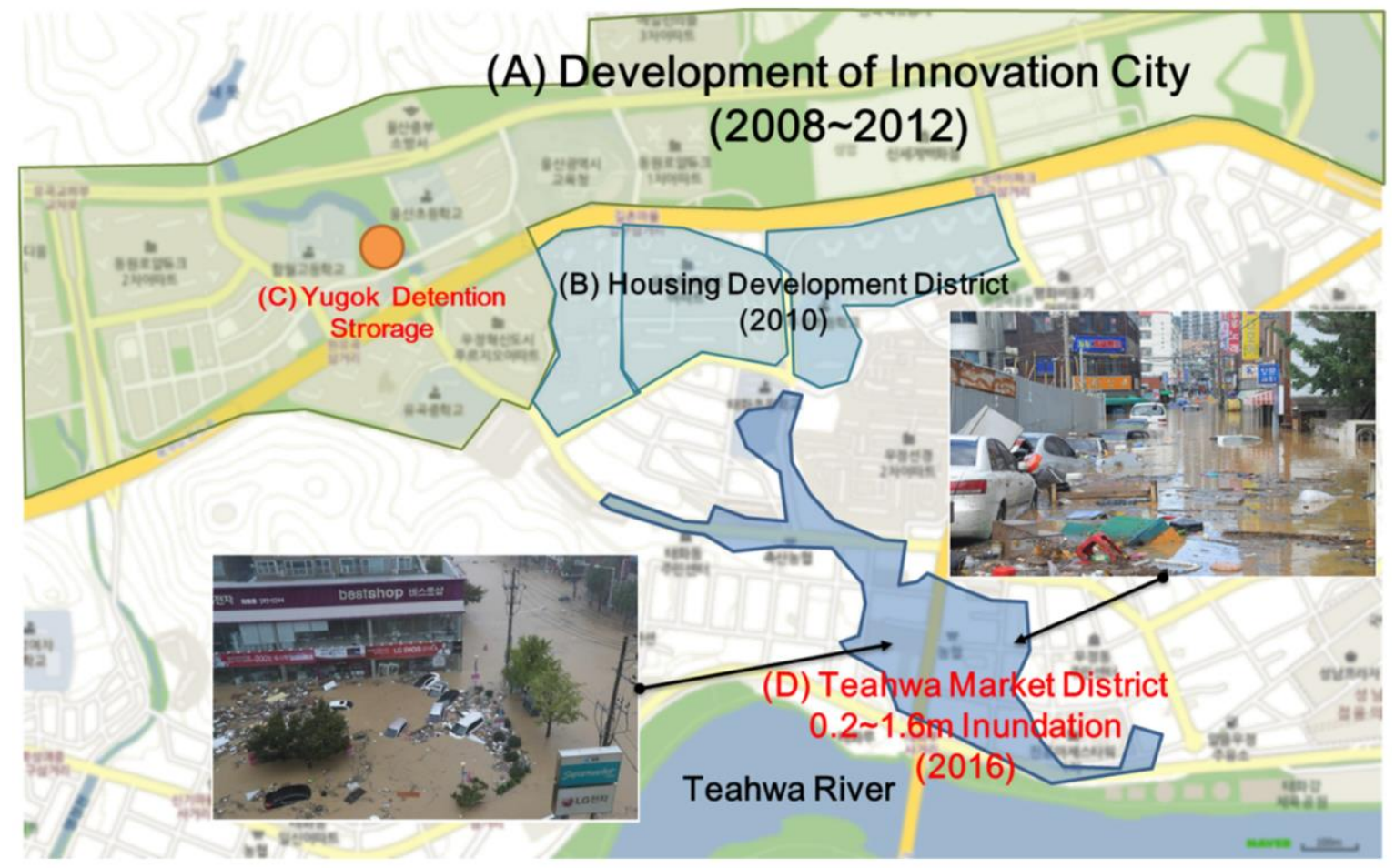

Figure 7. Typhoon "Chaba" Inundation Damage and Condition of Business District.

\subsubsection{Legal Aspects: Lack of Differentiation in the Plan and Project Guidelines}

The Development of Innovation City (A) in Figure 7 received a DIA at both the stage of establishing the administrative plan and the stage of the development project. However, the main risk reduction measures for the two DIAs constituted the single track of setting up Detention Storage (C). Although the Housing Development District (B) is legally subject to a disaster impact assessment, no such assessment was conducted.

This raises the first problem with the DIA. There is no differentiation in the contents of assessment because only the risk reduction measures for the same expected disasters are reviewed for the administrative plans and development projects. For development projects, measures against soil erosion, countermeasures against storm drainage, and drainage treatment plans can be established via quantitative analysis using basic data. However, for administrative plans, where the discussion regarding location is important, a high proportion of the disaster impact review must pertain to the surrounding areas, which corresponds to discussion regarding location, and the review of the disaster impact adequacy of the planned site. However, in actual assessments, no adequacy review of disaster impact is conducted. As a result, the discussion on the implementation plan level, which cannot be dealt with in administrative plans, is dealt with in the Practical Guidelines, and during preparation of the assessment report, the location is not sufficiently reviewed. Furthermore, the review of administrative plans focuses on implementation designs rather than on location, due to lack of basis data for judging the suitability of location, such as disaster risk maps. Therefore, as is evident, this problem is complex.

\subsubsection{Technical Aspects: Lack of Objectivity in the Disaster Impact Review}

No information (disaster risk map, etc.) was provided regarding the lack of measures to reduce inundation disasters, cited as the second major cause of flooding in Taehwa Market District (D) in Figure 7. Furthermore, objective evaluation of the DIA was difficult due to the lack of basic data on the risk of flooding in downstream Taehwa Market District (D), i.e., the areas surrounding the Development of Innovation City (A) and Housing Development District (B). 
Here, the second problem with the DIA emerges: the lack of review data for objective judgment of disaster risks. Since disaster risks are only reviewed for the project site, reliable disaster risk maps cannot be prepared. Although the disaster risks in the project site are evaluated relatively quantitatively, and countermeasures are established, the reviews of surrounding areas are only examined qualitatively due to lack of basic data. While there are some data indicating disaster risks in the basin unit for major rivers, these data indicate risks before development of the project site, and it is impossible to know the disaster risks and burdens that will be aggravated after development.

\subsubsection{Operational Aspects: Perfunctory Disaster Risk Reduction Measures}

According to the DIA on the Development of Innovation City (A) in Figure 7, only structural measures to install the Detention Storage (C) were established as a countermeasure due to the increase in flow rate. As a result, Typhoon 'Chaba' caused serious casualties, which could have been reduced if non-structural measures to transmit the risk to residents of Taehwa Market District (D) had played a role, i.e., through connection with detention measuring equipment and early warning facilities for water level rise in the Taehwa River.

Thus, the third problem is the use of perfunctory non-structural measures, which are presented by residents as alternatives that can, in principle, complement structural measures; in this sense, their connection with structural measures is crucial. However, most risk reduction facilities do not have significant effects because the warning and alert systems are operated independently. The established non-structural measures can be effective only through data sharing with surrounding systems to analyze the criteria and factors of system alerts and warnings, delivery and education of information regarding the personnel and material situation, and flood risk information regarding the damage expected areas to which risks should be communicated through alerts and warnings, plans for recovery after damage, and inducement of disaster insurance coverage, depending on the situation.

\subsection{Details of Improvements to the DIA SYSTEM}

When assessing the DIA System according to the qualitative assessment framework of regulatory policies, improvement in fairness, generalness, and professionality appears to be necessary (Table 5).

Table 5. Evaluation results and improvement needs of regulatory system.

\begin{tabular}{cccc}
\hline Division & Evaluation Results & Improvement Needs \\
\hline Openness & $\begin{array}{c}\text { Increase of DIA System's legal consultation and readjustment of area criteria } \\
\text { increases political support and participation of groups (Section 3.1.1) }\end{array}$ & Maintenance \\
Fairness & $\begin{array}{c}\text { Lack of fairness in selection of target scope due to DIA bias in administrative plan } \\
\text { (Section 3.1.2) }\end{array}$ & Improvement \\
& $\begin{array}{c}\text { Based on the results of the consultation and its method, the DIA System is } \\
\text { recognized as a formal administrative procedure and lacks procedural fairness } \\
\text { and formality of the responsible materials (Section 3.1.3). }\end{array}$ & Improvement \\
Generalness & $\begin{array}{c}\text { Lack of universalness and inclusiveness due to consultation of similar } \\
\text { administrative plans, development projects, and discriminatory consultation } \\
\text { (Section 4.2.1) }\end{array}$ & Improvement \\
\hline Professionality & $\begin{array}{c}\text { Lack of a post-management system compared to other systems such as EIA } \\
\text { System lacks a sense of balance for regulatory selection (Section 3.1.4) }\end{array}$ & \\
\hline & $\begin{array}{c}\text { Lack of technical competence and objectivity of DIA results by consultation staff } \\
\text { (Section 4.2.2) }\end{array}$ & \\
\hline
\end{tabular}

The DIA System needs to be overhauled to remove the perception that it is merely a bureaucratic box-ticking exercise required for the approval of development projects. Before an assessment report is prepared, prior review should be conducted to evaluate the assessment scope and items by analyzing the characteristics of the basin in which 
a development project is to be conducted. Furthermore, the adequate time for the DIA System should be determined during the approval process, considering the project purpose and characteristics. To establish risk reduction measures by more accurately predicting disaster impacts and reviewing the analysis results based on basic data in the early stage, the data of the implementation design stage may be required. For example, the design of a residential complex must reflect the design of derange pipes for accurate analysis of inland flooding in the complex. If the drainage pipe design condition can be a factor in inland flooding, the design must be adapted, or additional risk reduction measures established to prevent or reduce disasters.

The DIA reports that have been prepared since 1995 are still printed out, retained as documents, and distributed to assessors as booklets. However, a huge volume of data, covering 38,000 cases, is being neglected, damaged, or destroyed without being converted into a database. In 2008, a plan was established for collecting assessment reports through a database system, but it was subsequently discontinued owing to problems such as insufficient research and development funds and the maintenance of the operating server. To precisely identify possible disaster impacts by the type of administrative plans and development projects and to establish rational risk reduction measures, problems should be identified, and directions of improvement must be established based on past data. Furthermore, guidelines should be established based on the universal characteristics of each project type. To that end, a DIA System should be developed that can support analysis of various project types and simulation of risk reduction measures based on databases.

Each DIA report is reviewed by at least five persons for possible disaster impacts and risk reduction measures. Once the assessment results are derived according to the written and meeting deliberation types and the composition of deliberation committee members, the project approver collects the results and makes a decision of approval or disapproval. Typically, even if the project type is the same, the assessment results can differ depending on the deliberation type and composition of committee members. This is because the approver may lack the necessary expertise to objectively analyze, from a scientific mathematical basis, the assessment results; the committee members' abilities also vary. The approver is generally the head of the department in charge of disasters, and may be a non-expert due to rotation in personnel management. That is, a pool of 40 to 80 persons is organized to serve as deliberation members in the relevant region. However, while it is relatively easy to organize such pools in metropolitan cities, in small areas, it is difficult due to the small number of experts. For this reason, persons who do not understand the DIA System, who have low relevance, and who only satisfy the basic qualifications are evaluating projects. To obtain objective DIA results, the process should be altered to evaluate the qualifications or educate the deliberation committee members or to allow specialized assessment agencies to generally manage and assess all projects.

\section{Conclusions}

Since 1995, Korea has invested approximately USD 7.33 billion in national funds to prevent and reduce disasters through improvement of disaster risk areas, maintenance of small rivers, and installation of rainwater storage facilities. The Korean government has continuously conducted international disaster risk reduction programs through DIAs for administrative plans and development projects countrywide. However, these disaster prevention and risk reduction activities lack few necessary requirements for improving the disaster prevention abilities of the nation and provinces. According to the Korean statistics (2019 annual natural disaster yearbook), considering data from 2010 to 2019, the amount required for recovery from natural disasters was approximately USD 750 million, which is 2.3 times the amount of damage (USD 320 million). The Taehwa Market District area was designated as a natural disaster risk zone (February 2018), owing to the damage caused by flooding (Figure 7). Approximately, USD 45 million will be spent on improving the disaster zone. The installation cost of Detention Storage (Figure 7) is between USD 100,000 and USD $\$ 200,000$; therefore, the cost/benefit loss is significant. 
The central and local governments have established measures to reduce disasters resulting from development plans and projects using the DIA System. However, this system, which has been in operation for two decades, has maintained uniform guidelines that fail to reflect the detailed characteristics of the development types that are now being implemented. Due to the limited period available for predicting and evaluating disaster impacts, an operation principle based on written review, and lack of objectivity, the DIA System has degenerated to a perfunctory process before approval of development. If the disaster impact assessment system according to the development project had been properly operated, would it not have helped reduce the cost of recovery and improvement caused by natural disasters?

This study proposes several improvement measures for the development of Korea's DIA System. First, the review standards in the administrative plan should be improved. Currently, the administrative plan must qualitatively examine the adequacy of the location and the disaster-causing factors in terms of disaster occurrence. However, the same review method, standards, scope, and components for development plans and projects are applied, and this needs to be improved. The administrative plans must be reviewed in consideration of the scale and character of the urban basic plan and district unit plans established around the planned site. Furthermore, a guideline is required for considering the mutually organic relationships regarding the disaster-sharing plans of the surrounding areas that have overlapping schedules and that require interconnected review from the implementation of the plan and the completion of the development projects.

Second, the DIA System should be reinforced from a consultation system to an approval system. Legally, the current DIA System only requires consultation for administrative plans and the projects can be implemented once perfunctory measures have been established. For example, in the implementation plan for review items, the project organizers might say 'we will take measures for___ and 'we will improve ' to the review committee. To solve this problem, the process of monitoring and verifying the action plans and results by review committee members should be required. Furthermore, it should be a requirement to review of the measures discussed in the administrative plan when the review document for the development project is prepared so that the items consulted in the administrative plan are linked to the development project.

Third, non-structural measures should be established along with structural measures to prepare for disasters that have a frequency that is higher than the design frequency. The existing disaster risk reduction structures should be installed in accordance with the design standards, and non-structural measures should be included in the maintenance items to maintain the performance and effects through post-management. These measures might include disaster alert and warning system development, risk assessment, and disaster management education. Furthermore, the spatial analysis scope of the disaster alert and warning system and risk assessment system should be expanded to the project and surrounding areas, so that the disaster risk and load can be quantitatively analyzed after development and a disaster risk map can be produced and used for disaster education for residents. This will induce business operators to prepare more responsible action plans while recognizing the disaster risks resulting from their project, and to make efforts to reduce disasters.

In the future, the DIA System should systematize its operation, objectify assessment, and include review items that improve the limitations of structural measures for disaster risk reduction by applying non-structural measures. Furthermore, disaster prevention education should be conducted in local communities to make residents aware of the possibility that disasters could occur regularly. For disaster prevention education, residents and local governments should participate in discussion of previous damage cases, countermeasures, and lessons, rather than one-sided lectures, so that participants and institutions can share experiences and information. 
Author Contributions: Conceptualization, C.-J.K. and J.-S.K.; methodology, C.-J.K.; validation, C.-J.K. and J.-S.K.; formal analysis, C.-J.K.; investigation, C.-J.K.; resources, C.-J.K.; data curation, C.-J.K.; writing-original draft preparation, C.-J.K.; writing—review and editing, J.-S.K.; visualization, C.-J.K.; supervision, J.-S.K.; project administration, J.-S.K. All authors have read and agreed to the published version of the manuscript.

Funding: This research did not receive any specific grant from funding agencies in the public, commercial, or not-for-profit sectors.

Data Availability Statement: The authors confirm that the data supporting the findings of this study are available within the article.

Conflicts of Interest: No potential competing interest was reported by the authors.

\section{Notes}

1 The Consultation Agency is the principal responsible for conducting consultations on approval of a plan or project and is primarily a government department or government office.

2 The Development of an Innovative City (A) is an urban development project that reflected government policies to promote the relocation of public institutions concentrated in the capital. This development project includes public institutions, various residential facilities, and commercial facilities, and is subject to disaster impact assessment.

\section{References}

Cho, Sung Han. 2006. Regulation, the Tool of Governance. Journal of the Korean Society for Policy Science 10: 1-18. Available online: http: / / www.dbpia.co.kr/journal/articleDetail?nodeId=NODE01190757 (accessed on 14 October 2021).

Coglianese, Cary. 2012. Measuring Regulatory Performance: Evaluating the Impact of Regulation and Regulatory Policy. OECD Secretary-General Expert Paper No. 1. Available online: https:/ /www.oecd.org/gov/regulatory-policy/1_coglianese\%20web. pdf (accessed on 14 October 2021).

Kang, Sand Jun, JuChul Jung, and DalByul Lee. 2014. Improvement of Preliminary Disaster Inspection and Consultation System. Journal of the Korean Society for Disaster Prevention 14: 395-406. Available online: http://www.riss.kr/link?id=A103810479 (accessed on 14 October 2021).

Kim, Gyun Tae. 2007. Study on the Way of Improving Preliminary Disaster Inspection and Consultation System in the Viewpoint of Hands-on Workers. Water Future 40: 101-4. Available online: http://www.ndsl.kr/ndsl/commons/util/ndslOriginalView.do? $\mathrm{dbt}=\mathrm{JAKO} \& \mathrm{cn}=\mathrm{JAKO} 200707341629446$ (accessed on 14 October 2021).

Lee, Seung-Uh, Kyung Ho Cho, Tae-Yun Kim, and Jung-Yul Kim. 2003. A Research of Regulatory Evaluation Model for the Korea Central Government. Modern Society and Public Administration 13: 125-59. Available online: http://www.riss.kr/link?id=A76486 032 (accessed on 14 October 2021).

Lowi, Theodore J. 1972. Four Systems of Policy, Politics, and Choice. Public Administration Review 32: 298-310. [CrossRef]

Ministry of Environment. 2016. Environment Impact Assessment Promotion Booklet of the Ministry of Environment. Available online: http:/ / www.me.go.kr/home/file/readDownloadFile.do?fileId=141376\&fileSeq=1 (accessed on 10 August 2021).

Ministry of the Interior and Safety. 2020. 2019 Annual Natural Disaster Yearbooks. Available online: https://www.mois.go.kr/frt/ bbs/type001/commonSelectBoardArticle.do;jsessionid=9q+z++-8qP6PFH1L9NfdGfxr.node20?bbsId=BBSMSTR_0000000000 $14 \&$ nttId=81886 (accessed on 14 October 2021).

National Disaster Management Institute. 2009. Analysis of Hood Control Effects and Setup of Analysis Database on the Basin of Disaster Impact Assessment Program. Available online: http://www.ndsl.kr/ndsl/commons/util/ndslOriginalView.do?dbt= TRKO\&cn=TRKO201000011665. (accessed on 14 October 2021).

National Law Information Center. 2019. Practice Guide for Disaster Impact Assessment. Ministry of the Public Administration and Security Notification (No. 2019-5). Available online: http:/ / www.law.go.kr/admRulSc.do?tabMenuId=tab107\#liBgcolor0 (accessed on 14 October 2021).

Park, Bin-Hee. 2011. Current Situation and Improvement Way of the Preventive Disaster System through Predisaster Effect Examination System. Master's thesis, Hanbat University, Daejeon, Korea. Available online: http:/ / www.riss.kr/link?id=T12425651 (accessed on 14 October 2021).

Park, Sang-Woo. 2009. An Analytical Study of the Effect of Prior Consultations on how the Influencing Factors of Disasters are Examined. National Emergency Management Agency. Available online: http:/ / www.riss.kr/link?id=M12471834 (accessed on 14 October 2021).

Radaelli, Claudio M., and Oliver Fritsch. 2012. Measuring Regulatory Performance: Evaluating Regulatory Management Tools and Programs. Expert Paper No. 2, July. Available online: https:/ / www.oecd.org/gov/regulatory-policy/2_Radaelli\%20web.pdf (accessed on 14 October 2021).

Sakong, Young-Ho, Hye-Soo Ha, and Hae-Soo Kwon. 2000. Evaluating Regulatory Reform Efforts: The First Two Years of the Kim Dae-jung Administration. Korean Society and Public Administration Research 11: 43-60. Available online: http://www.dbpia.co.kr/ journal/articleDetail?nodeId=NODE00815673 (accessed on 14 October 2021). 
UNDRR Preventionweb. 2020. 2019 Global Natural Disaster Assessement Report. Available online: https://www.preventionweb.net/ publication/2019-global-natural-disaster-assessment-report (accessed on 14 October 2021).

World Bank Group. 2017. Investment Climate Advisory Services, Tools and Approaches to Review Existing Regulations. Available online: https:/ / elibrary.worldbank.org/doi/abs/10.1596/27876 (accessed on 14 October 2021). 